\title{
Advantage of HSP110 (T17) marker inclusion for microsatellite instability (MSI) detection in colorectal cancer patients
}

\author{
Gustavo Noriz Berardinelli ${ }^{1}$, Cristovam Scapulatempo-Neto ${ }^{1}$, Ronílson Durães ${ }^{1,2}$, \\ Marco Antônio de Oliveira ${ }^{3}$, Denise Guimarães ${ }^{1,4}$ and Rui Manuel Reis ${ }^{1,5,6}$ \\ ${ }^{1}$ Molecular Oncology Research Center, Barretos Cancer Hospital, Barretos, São Paulo, Brazil \\ ${ }^{2}$ Department of Oncology, Barretos Cancer Hospital, Jales, São Paulo, Brazil \\ ${ }^{3}$ Nucleus of Epidemiology and Biostatistics, Barretos Cancer Hospital, Barretos, São Paulo, Brazil \\ ${ }^{4}$ Department of Endoscopy, Barretos Cancer Hospital, Barretos, São Paulo, Brazil \\ ${ }^{5}$ Life and Health sciences Research Institute, University of Minho, Gualtar Campus, Braga, Portugal \\ ${ }^{6}$ ICVS/3B's-PT Government Associate Laboratory, Gualtar Campus, Braga, Portugal \\ Correspondence to: Rui Manuel Reis, email: ruireis.hcb@gmail.com \\ Keywords: colorectal cancer; microsatellite instability; molecular diagnostic; immunohistochemistry; HSP 110 (T17) \\ Received: November 02, $2017 \quad$ Accepted: April 04, $2018 \quad$ Published: June 19, 2018 \\ Copyright: Berardinelli et al. This is an open-access article distributed under the terms of the Creative Commons Attribution License \\ 3.0 (CC BY 3.0), which permits unrestricted use, distribution, and reproduction in any medium, provided the original author and \\ source are credited.
}

\section{ABSTRACT}

Colorectal cancer (CRC) is a leading cause of cancer death worldwide. Microsatellite instability (MSI) is a genetic pathway leading to CRC, associated with particular clinicopathological features, and recently a major biomarker of immunotherapy response. There is little information the frequency MSI among Brazilian CRC patients, and it is still debatable the ideal methodology for MSI screening in countries with limited resources. We proposed to evaluate MSI by molecular and immunohistochemistry (IHC) methods, to compare both methodologies and also to assess the inclusion of a novel microsatellite marker, HSP110 (T17). The molecular MSI evaluation was performed using a PCR-multiplex panel in a total of 1013 CRC patients. Mismatch repair (MMR) proteins (MLH1, MSH2, MSH6 and PMS2) expression were evaluated by IHC. HSP110 (T17) marker was analyzed by fragment analysis. Molecularly, $89.5 \%$ of cases were MSI-negative and $10.5 \%$ were MSI-positive. The IHC showed that $88.9 \%$ of cases exhibited MMR-proficient status, $10.2 \%$ were MMRdeficient and $0.9 \%$ was inconclusive. Genotyping of the HSP110 (T17) in 106 MSIpositive and 215 MSI-negative cases showed its alteration only among the MSIpositive cases. We observed agreement $(0.956$, Kappa Test) between both molecular and IHC methodologies, with only eight discordant results, and in this subset of cases the HSP110 (T17) corroborate the molecular findings. This study suggests the use of molecular assays over IHC for MSI analysis and proposes the inclusion HSP110 (T17) marker as a complementary analysis in discordant cases.

\section{INTRODUCTION}

Colorectal cancer (CRC) is a common diagnosis in high-income countries and its incidence is rising in middle-income countries, including Brazil [1-3]. In US, it is the second largest cause of cancer-related deaths when both sexes are combined [2]. Five-year survival rate is about $50 \%$, with no differences between high-income countries (49\% average) and low- and middle-income countries (44\% average) [1]. In Brazil, CRC is the third most common cause of cancer for men and the second for women with approximately 30,000 new cases diagnosed per year for both genders [3]. The incidence rates are increasing due to population aging, increasing smoking 
rates, changes in diet style and the absence of wide spread screening programs [4].

Initiation and progression of $\mathrm{CRC}$ involve different molecular mechanisms responsible for distinct clinicopathological features and behavior of tumors [5]. A large body of evidence suggests that tumor location (left versus right) drives carcinogenesis [5, 6], and genomics abnormalities occur in a non-random pattern in the evolution of adenoma-carcinoma then metastasis [7]. Chromosomal instability (CIN), microsatellite instability (MSI) and $\mathrm{CpG}$ island methylation phenotype (CIMP) are genetical pathways involved in the development of CRCs affecting oncogenes, tumor suppressor genes and DNA repair mechanisms [7, 8]. More recently, CRC have been subtyped molecularly in four consensus molecular subtypes (CMSs) based on gene expression with distinguishing features: CMS1 (microsatellite instability immune, 14\%), hypermutated, microsatellite unstable and strong immune activation; CMS2 (canonical, 37\%), epithelial, marked WNT and MYC signaling activation; CMS3 (metabolic, 13\%), epithelial and evident metabolic dysregulation; and CMS4 (mesenchymal, 23\%), prominent transforming growth factor-beta activation, stromal invasion and angiogenesis [9].

MSI occurs when Mismatch Repair (MMR) proteins (MLH1, MLH3, MSH2, MSH3, MSH6, PMS1, and PMS2) are absent due to mutations or promoter hypermethylation in hereditary and sporadic forms, respectively $[10,11]$. These DNA repair proteins are important to repair base-base mismatches occurring during DNA replication; thus their loss leads to an accumulation of DNA replication errors, particularly in areas of the genome with short repetitive nucleotide sequences, known as microsatellites [12]. Genes containing microsatellite regions are known as MSI-target genes and are involved in several functions related with carcinogenesis, such as DNA repair, DNA damage sensor, apoptosis, signalization, proliferation etc $[11,13]$. As the alterations occur in a random matter, the findings suggest a different progression of each MSI-positive tumor, a model in which the MSI mutator phenotype develops in gradual steps by successive alterations of the different MSI-target genes [11, 14-16].

Hereditary Nonpolyposis Colorectal Cancer (HNPCC) or Lynch Syndrome is the most frequent hereditary colorectal cancer syndromes and is the result of the presence of germline mutations in $M M R$ genes, mainly $M L H 1$ and $M S H 2$ with somatic inactivation of the remaining wild-type allele $[10,17]$. On the other hand, in sporadic CRC, MSI phenotype is less frequent (12-15\%) and is predominantly due to loss of $M L H 1$ function, caused by transcriptional silencing of the gene brought about by abnormal methylation of $M L H 1$ promoter region [18].

Clinically, MSI positive CRCs are associated with several features, such as proximal location, poorly differentiated histology, intense lymphocytic infiltration, favorable prognosis compared to MSI negative CRCs, and lower risk of metastasis $[6,19]$. There are also several evidences suggesting that MSI positive patients are less responsive to 5-Fluorouracil-based chemotherapy (5-FU), and more responsive to irinotecan based regimens [1922]. Recently, MSI phenotype was reported as a predictive biomarker of response to immunotherapy treatments, more specifically anti-PD-1 therapy [23, 24]. Therefore, MSI is a useful molecular marker not only for diagnostic and prognostic purposes, but also for therapy prediction response in $\mathrm{CRC}$ patients, being currently, a crucial biomarker for CRC management [24, 25].

Nowadays, immunohistochemistry (IHC) and molecular methods are the most common assays for MSI assessment in CRCs. IHC, will detect the loss expression of MMR proteins in tumor tissue compared to adjacent normal, thus resulting in presence or absence of MMR proteins expression (MMR-proficiency versus -deficiency) [22].

Molecularly, MSI status can be assessed by PCR analysis of informative microsatellite markers, either mononucleotide and dinucleotide repeats, which are further analyzed by capillary sequencing [26, 27]. An initial panel of genetic markers, known as Bethesda panel, was established at a National Cancer Institute's (NCI) workshop, and includes two mononucleotide (BAT25 and BAT26) and three dinucleotide (D5S346, D2S123, and $\mathrm{D} 17 \mathrm{~S} 250$ ) repeats; this assay requires including matchednormal DNA as a reference [26]. Later, a subsequent NCI's workshop re-evaluated the Bethesda panel and recommended the substitution of dinucleotide repeats by quasi-monomorphic mononucleotide repeat markers (BAT25, BAT26, NR21, NR24, and NR27), which allow performing the assay only in tumor DNA, thus avoiding the use of paired normal DNA [28]. This method classified tumors as high microsatellite instability (MSI-H) when at least two of five markers are instable, low microsatellite instability (MSI-L) when only one marker is instable and microsatellite stability (MSS) [27, 29].

Recently, we implemented an optimized molecular assay for MSI evaluation for the Brazilian population [27]. We established a quasi-monomorphic variation range (QMVR) for each marker in a Brazilian healthy population allowing the use of MSI markers without matching normal DNA, which was independent of the ethnicity, even in the highly admixed population of Brazil [27].

Recently it has been reported a high frequency of mutation of the HSP110 microsatellite T17 (mononucleotide repeat retained in intron 8) in MSIpositive CRC cases [14]. Changes in this region have been shown to be important because of their association with biological effects leading to an increased synthesis of a variant HSP110 isoform due to exon 9 skipping (HSP110DE9) [14, 15]. Chaperone proteins including HSP110 are expressed in specific set of stress conditions promoting the survival of malignant cells in colon 
cancers [30]. Deletions in HSP110 (T17) were shown to increase the sensitivity of CRC cells to 5-Fluorouracil and oxaliplatin [15]. Therefore, analysis of HSP110 (T17) was become an important tool for the identification of MSI-positive CRC cases and the appropriate clinical management of patients.

There is little information on MSI in Brazilian CRC patients and there is still some controversies concerning the ideal approach for MSI screening. So, in the present study we proposed to evaluate MSI by molecular and IHC methods in a large set of Brazilian CRC patients, to compare both methodologies, and to improve the analysis of discordant cases.

\section{RESULTS}

\section{Determination of MSI phenotype by MMR immunohistochemistry}

Expression analysis of MMR proteins (MLH1, MSH6, MSH2 and PMS2) was performed in 996/1013 CRC cases by immunohistochemistry (IHC). In a total of 17 cases there was not enough biological material for the analysis. Among those cases, 88.9\% (886/996) presented expression of the four MMR proteins, thus being considered positive, 10.2\% (102/996) exhibited loss of expression of at least one of the four MMR proteins and thus considered negative, and $0.9 \%$ (8/996) were considered inconclusive since the internal positive controls were negative (Figure 1A). Among the negative IHC cases, $52.0 \%(53 / 102)$ presented loss of MLH1/PMS2 and 20.6\% (21/102) loss of MSH2/MHS6. We also observed: 1.9\%, $2.9 \%, 7.9 \%$ and $6.9 \%$ of cases presenting isolated loss of MLH1, MSH2, MSH6 and PMS2, respectively. Other combinations of loss protein expression were observed in $7.8 \%(8 / 102)$ of cases and none of cases showed loss of expression of the all four proteins.

\section{Determination of MSI phenotype by molecular analysis}

All 1,013 CRC were analyzed for MSI by molecular analysis. We observed that $85.8 \%(870 / 1013)$ of cases were MSS, 3.7\% (37/1013) were MSI-L and 10.5\% (106/1013) were MSI-H (Figure 1B and Figure 2). We further grouped together the MSS and MSI-L cases, named: MSI-negative (MSS+MSI-L), while the MSI-H cases were named: MSI-positive [11, 16, 31].

\section{Validation, sensitivity, specificity and accuracy of molecular MSI analysis}

Using IHC as gold standard to determine the microsatellite instability, the agreement analysis between the methodologies was performed by the Kappa Test (Table 1). Considering that positive IHC status should represent MSI-negative status and that negative IHC status corresponding to MSI-positive status, we observed that the Measure of Agreement between the techniques was 0.956 $(\mathrm{p}<0.001)$ (Table 1).

Hence, the sensitivity, specificity and accuracy of the molecular MSI analysis was: $99.5 \%, 96.1 \%$ and $99.2 \%$, respectively (Table 2 ).

\section{Determination of HSP110 (T17) QMVR and tumor genotyping}

A recent report suggests HSP110 (T17) has value as a complementary marker in MSI determination [32]. In order to evaluate the role HSP110 (T17) in our cohort, we initially determined its quasi-monomorphic variation range (QMVR). For that, a total of 214 DNA from healthy subjects were analyzed to determine the normal range. All the 214 samples were successfully amplified, generating 428 alleles. The allele size was monomorphic with only two observed alleles: 131 and 132 base pairs. The $131 \mathrm{bp}$ allele was observed in 234/428 (54.7\%) alleles (Figure 3A) and the 132 base pair was seen in 194/428 (45.3\%) alleles. Therefore, we determined the HSP110 (T17) QMVR as $130-133 \mathrm{bp}$, since $\pm 1 \mathrm{bp}$ variations can occur from different reagents and equipment's used in the analyses [28, 33].

Following the QMVR determination, we further genotyped the HSP110 (T17) in the tumor tissue from CRC patients, namely in MSI-positive cases (MSI-H=106) and MSI-negative cases (subsets of MSS=180 and of MSI-L=35). In MSI-negative cases, all of them exhibited the HSP110 (T17) within QMVR above determined. In MSI-positive cases, 7.6\% (8/106) were inconclusive, due to very poor DNA quality. Among the conclusive cases we observed $5.1 \%(5 / 98)$ of cases without alterations, and $94.9 \%$ (93/98) with altered HSP110 (T17), exhibiting alleles with losses of up to $6 \mathrm{bp}$ in relation to the QMVR (Figure 3B) and aberrant peak ratios.

\section{Discordant IHC and molecular MSI results}

Despite the high agreement between IHC and molecular methodologies, we observed discordant results in eight cases (Table 3, Supplementary Table 1). In these cases, we assessed the HSP110 (T17) marker, which showed to be alterated in the four MSI-H/positive-IHC cases (Table 3, Supplementary Table 1). The two MSS/negative-IHC and two MSI-L/negative-IHC cases also showed presence of HSP110 (T17) alteration (Table 3, Supplementary Table 1).

\section{DISCUSSION}

In colorectal cancer (CRC), the presence of MSI has been used as a biomarker for several purposes: i) hereditary screening; ii) prognostic marker, where stage II/III tumors presenting MSI have a better prognosis than those that do not present it; iii) 5-FU resistance 
Table 1: Measure of Agreement (Kappa Test) between immunohistochemistry (IHC) and molecular MSI analyses

\begin{tabular}{lcc}
\hline IHC status (n) & Molecular MSI status (n) & Measure of Agreement \\
\hline MSI- (886) & MSI- (882) & \\
\cline { 2 - 3 } & MSI+ (4) & $0.956(\mathrm{p}<0,001)$ \\
\cline { 2 - 3 } & MSI-(4) & \\
\hline
\end{tabular}

+: positive, -: negative, n: number of cases

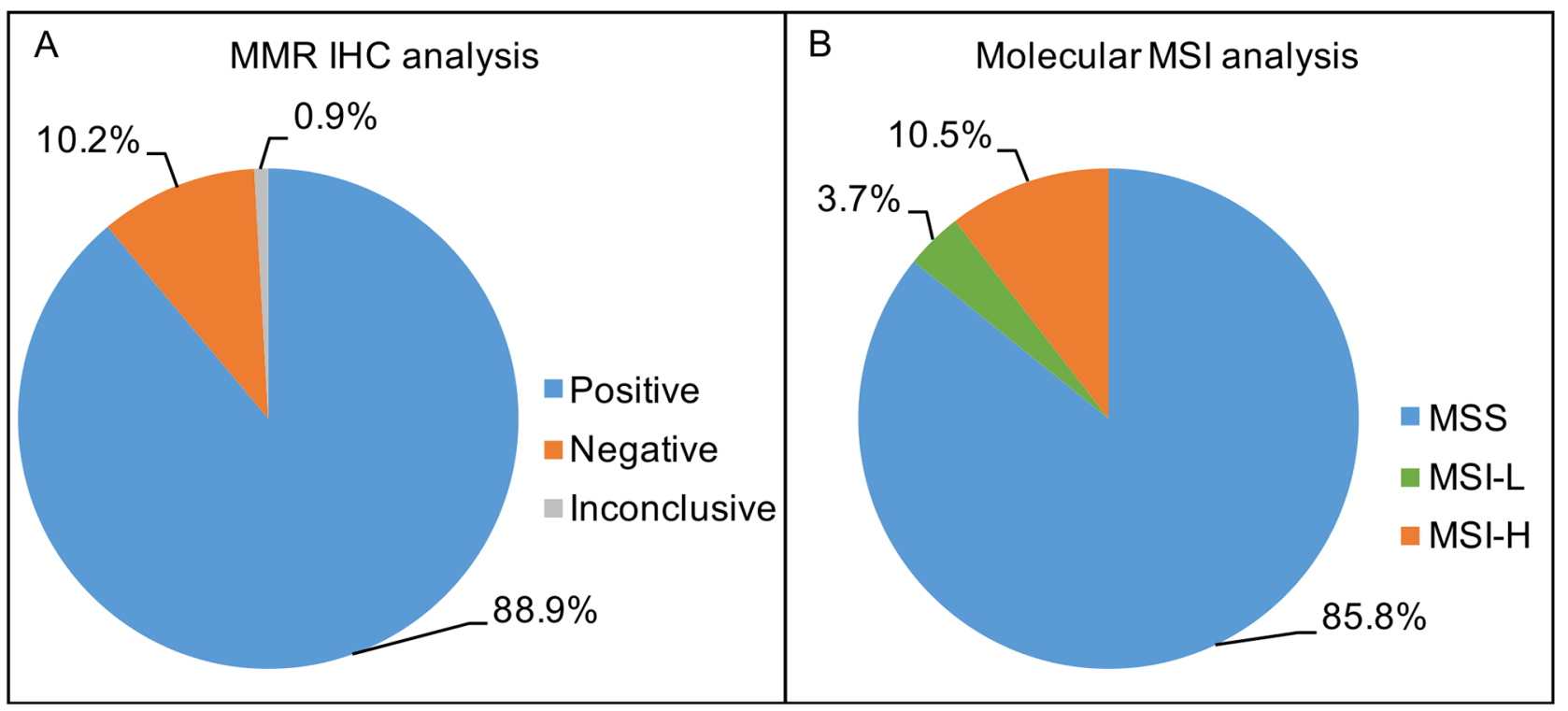

Figure 1: (A) Percentage of MMR IHC status for 996 Brazilian CRC patients; Positive IHC status: 88.9\% (886/996), Negative IHC status: $10.2 \%$ (102/996) and Inconclusive IHC status 0.9\% (8/996). (B) Percentage of molecular MSI status for 1013 Brazilian CRC patients; MSS (microsatellite stability): 85.8\% (870/1013), MSI-L (low-microsatellite instability): 3.7\% (37/1013) and MSI-H (high-microsatellite instability): $10.5 \%$ (106/1013).

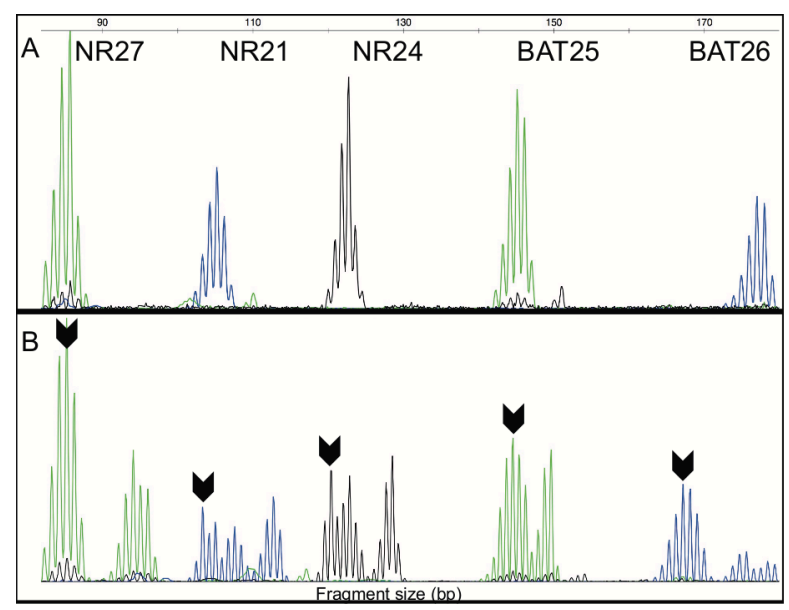

Figure 2: (A) Fragment analysis of peaks for molecular MSI analysis in one MSS CRC sample with five markers (NR27, NR21, NR24, BAT25 and BAT26) within of the quasi-monomorphic variation range (QMVR). (B) Fragment analysis of peaks for molecular MSI analysis in one MSI-H CRC sample with five markers (NR27, NR21, NR24, BAT25 and BAT26) outside of the QMVR. Arrow indicates the allele outside of the QMVR. bp - base pair. 
Table 2: Estimation of sensitivity, specificity and accuracy of molecular MSI analysis

\begin{tabular}{lccc}
\hline & IHC-negative (n) & IHC-positive (n) & Total \\
\hline MSI-positive (MSI-H) & 98 & 4 & 102 \\
\cline { 2 - 4 } MSI-negative (MSS+MSI-L) & 4 & 882 & 886 \\
\hline Total & 102 & 886 & 988 \\
\hline
\end{tabular}

MSS: microsatellite stability, MSI-L: low-microsatellite instability, MSI-H: high-microsatellite instability, n: number of cases.

Table 3: Summary of cases with discordant data between immunohistochemistry and molecular MSI analysis

\begin{tabular}{|c|c|c|c|c|c|c|c|}
\hline Sample ID & IHC status & MLH1 & MSH2 & MSH6 & PMS2 & $\begin{array}{c}\text { Molecular MSI } \\
\text { status }\end{array}$ & $\begin{array}{c}H S P 110(\mathrm{~T} 17) \\
\text { status }\end{array}$ \\
\hline 11.0011 & negative & + & + & + & - & MSS & altered $^{\mathrm{a}}$ \\
\hline 12.0767 & negative & - & + & + & - & MSS & altered $^{\mathrm{a}}$ \\
\hline 11.0226 & negative & + & + & - & + & MSI-L & altered $^{\mathrm{a}}$ \\
\hline 13.0395 & negative & + & + & + & - & MSI-L & altered $^{\mathrm{a}}$ \\
\hline 11.0404 & positive & + & + & + & + & MSI-H & altered \\
\hline 11.0827 & positive & + & + & + & + & MSI-H & altered \\
\hline 13.0578 & positive & + & + & + & + & MSI-H & altered \\
\hline 13.1023 & positive & + & + & + & + & MSI-H & altered \\
\hline
\end{tabular}

HSP110 (T17) status obtained by comparison between normal and tumor tissue DNA from the samples and also by R method. +: positive protein expression; -: negative protein expression; MSS: microsatellite stability; MSI-L: low-microsatellite instability; MSI-H: high-microsatellite instability; ${ }^{\text {a. }}$ analyzed by R method.

and irinotecan sensitivity [34]; and more recently iv) immunotherapy response $[23,24]$.

Therefore, the identification of MSI plays a major role in cancer management and different analytical methodologies are currently used, being immunohistochemistry (IHC) and molecular testing (microsatellite markers) the most widespread. Both techniques are suggested in the American Society of Clinical Oncology (ASCO) and National Comprehensive Cancer Network (NCCN) guidelines for evaluation of MSI $[35,36]$. The methodology of choice can be associated a several factor, such as expertise of the laboratory, availability of technology and overall costs. In the present study we intended to compare different methodologies in a Brazilian routine setting. We analyzed 1,013 CRC cases and used a pentaplex PCR assay previously validated by our group in the Brazilian population [27]. We observed $85.8 \%$ of MSS cases, $3.7 \%$ of MSI-L cases and $10.5 \%$ of MSI-H cases. By IHC analysis, we observed that $10.2 \%$ of the cases exhibited MSI, with a Measure of Agreement (Kappa test) of 0.956 between both IHC and molecular methods. Besides the high level of agreement, the sensitivity, specificity and accuracy of the molecular test were $99.5 \%, 96.1 \%$ and $99.2 \%$, respectively, when the IHC was used as the gold standard. Our results are in accordance with previous series. Patil et al [37] used a panel of five markers similar to those used in our study and the agreement between the techniques was $100 \%$. Cicek et al [38] used a panel that included mononucleotide and dinucleotide markers and the cases identified by MSI and IHC were highly concordant when using the cutoff of $30 \%$ or greater for instable molecular markers. Zhang [39] compared both methods and concluded that molecular MSI is as sensitive and specific as IHC, given its excellent reproducibility and its potential capability to indicate mutations not be detected by IHC. Molecular MSI has been used and will continue to prevail as the primary screening tool for identifying HNPCC patients. To some extent, molecular MSI and IHC are complementary to each other in identifying HNPCC [39]. Lindor et al [40] evaluated both methods and the predictive value of abnormal IHC was $100 \%$ for an MSI-H phenotype and that testing strategies must take into account acceptability of missing some cases of MSI-H tumors if only IHC is performed. At variance, Lin et al [41] obtained 23 $(32.9 \%)$ discordant cases for the same comparison between methodologies. The panel of molecular markers used by Lin et al [41] may justify this high percentage of discordance, where, dinucleotide markers are known to be less sensitive compared to mononucleotide markers 
[42], which were used in our study. In addition, it was been reported that the molecular analysis is less prone to change than IHC due to neoadjuvant and radiation therapy in CRC, therefore, the ideal methodology, to assess MSI status after neoadjuvant therapy [43].

Despite the high agreement among methodologies, we observed disagreement in eight cases. Recently, HSP110 (T17) marker has been proposed as a complementary marker in MSI assessment [32]. Therefore, we initially determined the QMVR of HSP110 (T17) in a Brazilian healthy population. This analysis showed the monomorphic nature of the marker. We further assess this marker in MSI-positive cases and observed 94.9\% with altered HSP110 (T17). This value was as high as the values obtained by Dorard et al [14], Collura et al [15], Buhard et al [32] and Markovic et al [44] of HSP110 (T17) changes in MSI-positive cases, which reported a frequency of $100 \%, 97 \%, 98.7 \%$ and $100 \%$, respectively. Altogether, these results suggest that HSP110 is the most mutated MSI-target gene in MSI-positive CRC [14]. Importantly, in the discordant cases, all four MSI-H/IHCpositive cases presented alteration in HSP110 (T17), and in the two MSS/IHC-negative cases and in the two MSI-L/ negative-IHC cases the HSP110 (T17) was also alterated, suggesting a higher sensitivity of HSP110 (T17) to detec
MSI compared to pentaplex, in agreement with recent findings of Buhard et al [32].

The HSP110, like other heat shock proteins (HSP), protects cells against adverse conditions, acts as a nucleotide exchange factor for HSP70 and acts as a major chaperone $[45,46]$. Because of this activity, HSP110 is a good antigen-carrying protein and is used as an extracellular protein in the vaccine formulation [47]. Although, its tumorigenic properly is not fully understood, in CRC is suggested to preventing cells to entry in apoptosis [48].

Both techniques compared herein are routinely used and each one has advantages and disadvantages. IHC has the advantages of being applicable in formalinfixed, paraffin-embedded tissues (FFPE), easy to perform, affordable, and able to guide the mutation screening of MMR genes. On the other hand, IHC can only assess a limited number of proteins, it is vulnerable to the quality of tissue preparation, and heavily depends on pathologist interpretation [39, 49]. The molecular technique has several advantages: i) it is applicable in formalin-fixed paraffin-embedded tissues (FFPE); ii) it does not need an expert pathologist for analysis; iii) it is objective and highly accurate compared to the subject evaluation of the staining pattern of the IHC slides; iv) it can identify

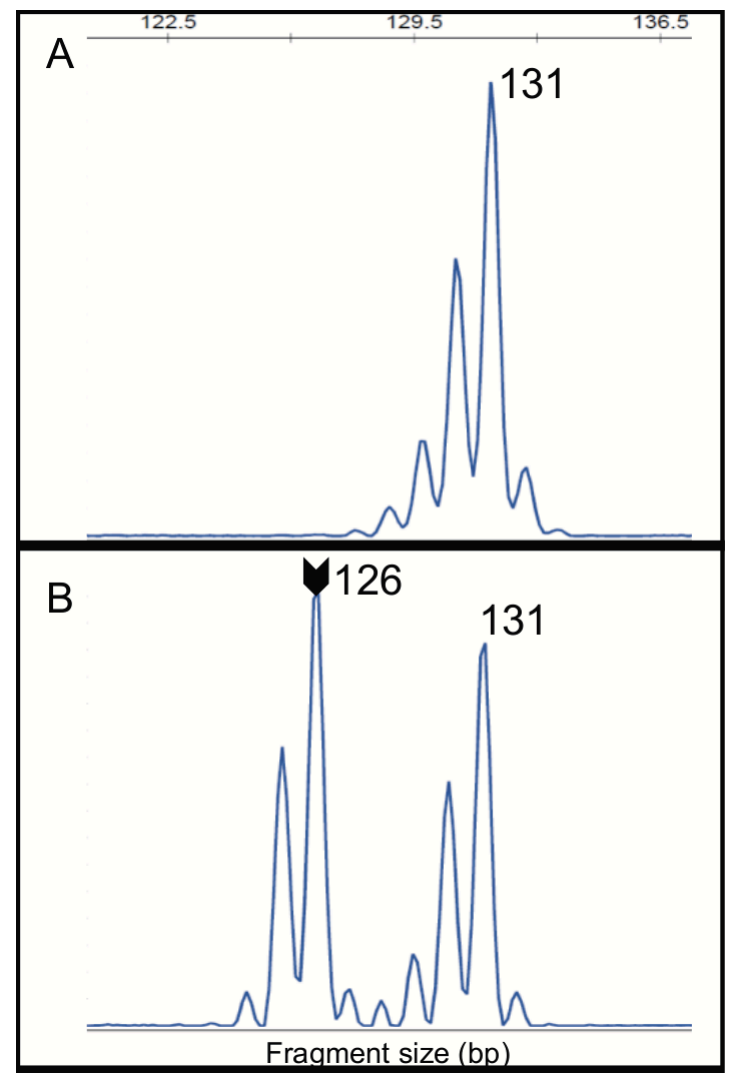

Figure 3: (A) The allele 131 of HSP110 (T17) marker was the most observed in 54.7\% (234/428) of analyzed alleles from healthy individuals blood DNA. (B) Two alleles (131 and 126) of HSP110 (T17) marker were observed in MSI-H CRC tumor DNA showing alteration in this marker. Arrow indicates the allele outside of the QMVR. bp - base pair. 
MSI-positive tumors that present defects in MMR but have protein staining due to a non-truncated missense mutation or to mutations in other MMR proteins which are not included in the IHC panel; v) it is feasible in small biopsies [50]; vi) is less disposed to change than IHC following neoadjuvant and radiation therapy, and vii) it has a low cost per patient when the assay is performed in-house. However, it has the disadvantage of the need of a molecular genetic facility and specialized staff, and like the IHC, the FFPE pre-analytic issues, such as tissue fixation, can also interfere with PCR reaction [22, 37, 39]. In the present study we used an optimize in-house assay that does not need matched adjacent normal tissue [27], thus leading to a more cost-efficient assay when compared with four immunohistochemistry (MLH1, MSH2, MSH6 and PMS2) reactions. Despite of the similar results, our findings suggest that the molecular MSI assay, with the use of pentaplex plus HSP110 (T17) marker leads to a more accurate MSI determination and it is less sensitive to pre-analytic issues in compared with IHC. Therefore, it is the ideal methodology for the routine assessment of MSI for CRC management in a low resource country as Brazil.

We observed an MSI-positive frequency of 10\%, which is in line with international reports that vary between $12-16 \%$ of CRC patients $[8,51,52]$. The slightly lower frequency described can be due to several factors, such as: tumor staging; different criteria for inclusion of patients, different ethnicities of the patients' analyzed, and environmental criteria that may affect the presence of MSI in the CRC.

In conclusion, the present study elucidated the MSI frequency in a robust manner by analyzing a large series of Brazilian CRC patients, who exhibited a known admixture ancestry [27]. Our results suggests that molecular analysis correlates better with the MSI phenotype in the CRC, and the HSP110 (T17) improves the MSI determination in a routine setting of a Brazilian Cancer Hospital.

\section{MATERIALS AND METHODS}

\section{Participants}

In the present study 1013 CRC patients diagnosed between 2010 and 2014 at Barretos Cancer Hospital, Barretos, São Paulo, Brazil were enrolled. CRC patients were referred by the Departments of Digestive Surgery and Oncogenetic for MSI testing. Surgery-based cases presented CRC with no information of the hereditary context, whereas the Oncogenetic-based cases had confirmed or high clinical suspicion of familial CRC syndromes. Patients came mainly from the Southeast region of Brazil $(77,7 \%)$, followed by Midwest $(8,6 \%)$ and Northeast $(8,1 \%)$, and few from the other Brazilian regions. Of the total of 1013 cases, 96.3\% (976/1013) were Surgery-based cases and 3.7\% (37/1013) were Oncogenetic-based cases, being 1.8\% (18/1013) confirmed
Lynch syndrome cases, 1.5\% (15/1013) confirmed Familial Adenomatous Polyposis (FAP) syndrome cases and $0.4 \%(4 / 1013)$ of unclassified hereditary syndrome. Among patients, $52.1 \%$ were male and the mean age was 57.8 years (standard deviation 13.9 years). Concerning tumor location, $25.2 \%$ were right sided, $51.3 \%$ located at left colon/proximal rectum and $23.5 \%$ at middle rectum/ distal rectum.

We also evaluated 214 healthy individuals from the BioBank at Barretos Cancer Hospital, Barretos, São Paulo, Brazil. The average age of the individuals was 33 years old, $52.3 \%$ were male, and $90 \%$ of the individuals came from the Southeast region of Brazil (São Paulo and Minas Gerais states), whereas others came from Paraná, Rio Grande do Sul, Bahia, Mato Grosso, Mato Grosso do Sul, Paraíba, Pernambuco, and Rondônia regions. This study was approved by the IRB at our institution (600/2012).

\section{DNA isolation}

Tumor FFPE DNA were isolated using QIAamp DNA Micro Kit (Qiagen, Hilden, Germany) following the manufacturer's instructions. DNA was isolated from 5 - $\mu \mathrm{m}$ formalin fixed paraffin-embedded (FFPE) tissue slides. Briefly, tissues were deparaffinized by a serial extraction with xylene and ethanol (100\%, 70\%, 50\%), and separately pathologist selected tumor areas were macrodissected using a sterile needle and carefully collected into a 1,5 mL PCR tube.

Blood DNA from healthy individuals was isolated using QIAamp DNA Blood Mini Kit (Qiagen, Hilden, Germany) following the manufacturer's instructions.

\section{Mismatch repair immunohistochemistry}

FFPE tissue blocks were cut into $3 \mu \mathrm{m}$ sections for immunohistochemistry (IHC) using Dako EnVision ${ }^{\mathrm{TM}}$ FLEX detection system Kit (Dako, Glostrup, Denmark) and Autostainer Link 48 equipment (Dako, Glostrup, Denmark) following the manufacturer's instructions. Antigen retrieval process was done at $97^{\circ} \mathrm{C}$ by 20 minutes $(\mathrm{pH} 9.0)$. Endogenous peroxidases were blocked with EnVision ${ }^{\mathrm{TM}}$ FLEX Peroxidase-Blocking Reagent (Dako, Glostrup, Denmark). The primary antibodies anti-human used in this study were: FLEX monoclonal mouse anti-MutL protein homolog 1 (MLH1) (clone ES05, ref IS079, ready-to-use, Dako, Glostrup, Denmark); FLEX monoclonal mouse anti-MutS protein homolog 2 (MSH2) (clone FE11, ref IR085, ready-to-use, Dako, Glostrup, Denmark); FLEX monoclonal rabbit anti-postmeiotic segregation increased 2 (PMS2) (clone EP51, ref IR087, ready-to-use, Dako, Glostrup, Denmark); and FLEX monoclonal rabbit antiMutS protein homolog 6 (MSH6) (clone EP49, ref IR086, ready-to-use, Dako, Glostrup, Denmark). The DAB solution was used for immunostaining visualization. Slides were counterstained with hematoxylin. Nuclear staining 
of normal epithelial cells, lymphocytes, and stromal cells served as positive internal controls in each case. All cases were analyzed by one expert pathologist (CSN) who, based on nuclear staining, classified each protein by its expression. Regardless of the intensity or the extent of cell staining, the positive status was found for the cases that showed staining (presence of the expression of the protein under analysis) and the negative status when no staining was present (absence of expression of the protein under analysis).

\section{Molecular microsatellite instability (MSI)}

The MSI evaluation was performed using a multiplex PCR comprising five quasi-monomorphic mononucleotide repeat markers (BAT25, BAT26, NR21, NR24, and NR27) as reported [27]. Primer sequences were described elsewhere [28]. Each antisense primer was end labeled with a fluorescent dye: FAM for BAT26 and NR21; VIC for BAT25 and NR27; and NED for NR24. PCR was performed using the Qiagen Multiplex PCR Kit (Qiagen, Hilden, Germany), with $1 \mu$ of DNA at $50 \mathrm{ng} / \mu \mathrm{l}$ and the following thermocycling conditions: $15 \mathrm{~min}$ at $95^{\circ} \mathrm{C}$; 40 cycles of $95^{\circ} \mathrm{C}$ for $30 \mathrm{~s}, 55^{\circ} \mathrm{C}$ for $90 \mathrm{~s}$ and $72^{\circ} \mathrm{C}$ for $30 \mathrm{~s}$; and a final extension at $72^{\circ} \mathrm{C}$ for $40 \mathrm{~min}$. PCR products were then submitted to capillary electrophoresis on an ABI 3500XL Genetic Analyzer (Applied Biosystems, Foster City, USA) according to the manufacturer's instructions. The results were analyzed using GeneMapper v4.1 (Applied Biosystems, Foster City, USA) software to measure the fragment length in base pairs.

Cases with 2 or more markers out of quasimonomorphic variation range (QMVR) were classified as MSI-H (MSI-High), cases with only one marker out of QMVR were classified as MSI-L (MSI-Low) and cases without markers out of QMVR were classified as MSS (Microsatellite stability), as reported [27].

\section{Determination of the HSP110 (T17) QMVR}

Blood DNA samples from 214 healthy individuals were used to determine the quasi-monomorphic variation range (QMVR) of HSP110 (T17). The determined QMVR was tested in MSI-negative $\mathrm{CRC}$ cases $(\mathrm{MSS}=180$ and MSI-L=37) and in MSI-positive CRC cases (MSI-H=90), with DNA samples extracted from FFPE cancer tissue.

PCR was performed using $5 \mu \mathrm{L}$ of Qiagen Multiplex PCR Kit (Qiagen, Hilden, Germany), $1 \mu \mathrm{L}$ of primers [1 mM] (Forward primer: 5'TGGGAAGTGTTCATGTGCTC3' and Reverse primer: 5'TGAATCATGGTTCCAGATCAGA3'), $3 \mu \mathrm{L}$ of water and $1 \mu \mathrm{l}$ of DNA at $50 \mathrm{ng} / \mu \mathrm{l}$ and the following thermocycling conditions: $15 \mathrm{~min}$ at $95^{\circ} \mathrm{C} ; 30$ cycles of $94^{\circ} \mathrm{C}$ for $30 \mathrm{~s}, 55^{\circ} \mathrm{C}$ for $90 \mathrm{~s}$ and $72^{\circ} \mathrm{C}$ for $30 \mathrm{~s}$; and a final extension at $72^{\circ} \mathrm{C}$ for $40 \mathrm{~min}$. PCR products were then submitted to capillary electrophoresis on an ABI 3500XL Genetic Analyzer (Applied Biosystems, Foster
City, USA) according to the manufacturer's instructions and the results were analyzed using GeneMapper v4.1 (Applied Biosystems, Foster City, USA) software.

HSP110 (T17) was also analyzed by $\mathrm{R}$ method, whose determination was calculated using the height ratios between peaks, namely R1 (between T14 and T16) and R2 (between T15 and T16), as described [31].

\section{Author contributions}

Conceived and designed the experiments: GNB, RMR. Performed the experiments: GNB, CSN. Analyzed the data: GNB, CSN, RD, MAO, DPG, RMR. Contributed reagents/materials/analysis tools: GNB, CSN, RD, MAO, DPG, RMR. Wrote the initial manuscript: GNB, RMR. Revised the manuscript: GNB, CSN, RD, MAO, DPG, RMR. Supervised the study: RMR.

\section{ACKNOWLEDGMENTS}

The authors would like to thank Dr Marta VianaPereira for her technical advices and Dr Eduardo Vilar for his critical review of the manuscript.

\section{CONFLICTS OF INTEREST}

The authors declare no potential conflicts of interest.

\section{FUNDING}

The present study was partially supported by a MCT/FINEP/CT-INFRA- PROINFRA 02/2010 grant.

\section{REFERENCES}

1. Goss PE, Lee BL, Badovinac-Crnjevic T, Strasser-Weippl K, Chavarri-Guerra Y, St Louis J, Villarreal-Garza C, Unger-Saldana K, Ferreyra M, Debiasi M, Liedke PE, Touya D, Werutsky G, et al. Planning cancer control in Latin America and the Caribbean. Lancet Oncol. 2013; 14:391436. https://doi.org/10.1016/S1470-2045(13)70048-2.

2. Siegel RL, Miller KD, Jemal A. Cancer Statistics, 2017. CA Cancer J Clin. 2017; 67:7-30. https://doi.org/10.3322/caac.21387.

3. INCA. Estimativa 2016: Incidência de Câncer no Brasil. Rio de Janeiro: INCA. 2016: 124.

4. Meyerhardt JA, Mayer RJ. Systemic therapy for colorectal cancer. N Engl J Med. 2005; 352:476-87. https://doi.org/10.1056/NEJMra040958.

5. Yahagi M, Okabayashi K, Hasegawa H, Tsuruta M, Kitagawa Y. The worse prognosis of right-sided compared with left-sided colon cancers: a systematic review and meta-analysis. J Gastrointest Surg. 2016; 20:648-55. https://doi.org/10.1007/s11605-015-3026-6. 
6. Lee MS, Menter DG, Kopetz S. Right versus left colon cancer biology: integrating the consensus molecular subtypes. J Natl Compr Canc Netw. 2017; 15:411-9.

7. Markowitz SD, Bertagnolli MM. Molecular origins of cancer: molecular basis of colorectal cancer. N Engl J Med. 2009; 361:2449-60. https://doi.org/10.1056/NEJMra0804588.

8. Boland CR, Goel A. Microsatellite instability in colorectal cancer. Gastroenterology. 2010; 138:2073-87.e3. https://doi.org/10.1053/j.gastro.2009.12.064.

9. Guinney J, Dienstmann R, Wang X, de Reynies A, Schlicker A, Soneson C, Marisa L, Roepman P, Nyamundanda G, Angelino P, Bot BM, Morris JS, Simon IM, et al. The consensus molecular subtypes of colorectal cancer. Nat Med. 2015; 21:1350-6. https://doi.org/10.1038/nm.3967.

10. Lynch HT, Snyder CL, Shaw TG, Heinen CD, Hitchins MP. Milestones of lynch syndrome: 1895-2015. Nat Rev Cancer. 2015; 15:181-94. https://doi.org/10.1038/nrc3878.

11. Kim TM, Laird PW, Park PJ. The landscape of microsatellite instability in colorectal and endometrial cancer genomes. Cell. 2013; 155:858-68. https://doi.org/10.1016/j.cell.2013.10.015.

12. Sinicrope FA, Sargent DJ. Molecular pathways: microsatellite instability in colorectal cancer: prognostic, predictive, and therapeutic implications. Clin Cancer Res. 2012; 18:1506-12. https://doi.org/10.1158/1078-0432.CCR-11-1469.

13. Shima K, Morikawa T, Yamauchi M, Kuchiba A, Imamura Y, Liao X, Meyerhardt JA, Fuchs CS, Ogino S. TGFBR2 and BAX mononucleotide tract mutations, microsatellite instability, and prognosis in 1072 colorectal cancers. PLoS One. 2011; 6:e25062. https://doi.org/10.1371/journal.pone.0025062.

14. Dorard C, de Thonel A, Collura A, Marisa L, Svrcek M, Lagrange A, Jego G, Wanherdrick K, Joly AL, Buhard O, Gobbo J, Penard-Lacronique V, Zouali H, et al. Expression of a mutant HSP110 sensitizes colorectal cancer cells to chemotherapy and improves disease prognosis. Nat Med. 2011; 17:1283-9. https://doi.org/10.1038/nm.2457.

15. Collura A, Lagrange A, Svrcek M, Marisa L, Buhard O, Guilloux A, Wanherdrick K, Dorard C, Taieb A, Saget A, Loh M, Soong R, Zeps N, et al. Patients with colorectal tumors with microsatellite instability and large deletions in HSP110 T17 have improved response to 5-fluorouracilbased chemotherapy. Gastroenterology. 2014; 146:401-11 e1. https://doi.org/10.1053/j.gastro.2013.10.054.

16. Hause RJ, Pritchard CC, Shendure J, Salipante SJ. Classification and characterization of microsatellite instability across 18 cancer types. Nat Med. 2016; 22:134250. https://doi.org/10.1038/nm.4191.

17. Stoffel EM, Kastrinos F. Familial colorectal cancer, beyond Lynch syndrome. Clin Gastroenterol Hepatol. 2014; 12:1059-68. https://doi.org/10.1016/j.cgh.2013.08.015.

18. Li X, Yao X, Wang Y, Hu F, Wang F, Jiang L, Liu Y, Wang D, Sun G, Zhao Y. MLH1 promoter methylation frequency in colorectal cancer patients and related clinicopathological and molecular features. PLoS One. 2013; 8:e59064. https://doi.org/10.1371/journal.pone.0059064.
19. Kheirelseid EA, Miller N, Chang KH, Curran C, Hennessey E, Sheehan M, Kerin MJ. Mismatch repair protein expression in colorectal cancer. J Gastrointest Oncol. 2013; 4:397-408. https://doi.org/10.3978/j.issn.2078-6891.2013.021.

20. Hartman DJ, Brand RE, Hu H, Bahary N, Dudley B, Chiosea SI, Nikiforova MN, Pai RK. Lynch syndrome-associated colorectal carcinoma: frequent involvement of the left colon and rectum and late-onset presentation supports a universal screening approach. Hum Pathol. 2013; 44:2518-28. https://doi.org/10.1016/j.humpath.2013.06.012.

21. Devaud N, Gallinger S. Chemotherapy of MMRdeficient colorectal cancer. Fam Cancer. 2013; 12:301-6. https://doi.org/10.1007/s10689-013-9633-z.

22. Lech G, Slotwinski R, Krasnodebski IW. The role of tumor markers and biomarkers in colorectal cancer. Neoplasma. $2014 ; 61: 1-8$.

23. Le DT, Uram JN, Wang H, Bartlett BR, Kemberling $\mathrm{H}$, Eyring AD, Skora AD, Luber BS, Azad NS, Laheru D, Biedrzycki B, Donehower RC, Zaheer A, et al. PD-1 Blockade in Tumors with MismatchRepair Deficiency. N Engl J Med. 2015; 372:2509-20. https://doi.org/10.1056/NEJMoa1500596.

24. Le DT, Durham JN, Smith KN, Wang H, Bartlett BR, Aulakh LK, Lu S, Kemberling H, Wilt C, Luber BS, Wong F, Azad NS, Rucki AA, et al. Mismatch repair deficiency predicts response of solid tumors to PD-1 blockade. Science. 2017; 357:409-13. https://doi.org/10.1126/science.aan6733.

25. Schmoll HJ, Van Cutsem E, Stein A, Valentini V, Glimelius B, Haustermans K, Nordlinger B, van de Velde CJ, Balmana J, Regula J, Nagtegaal ID, Beets-Tan RG, Arnold D, et al. ESMO Consensus Guidelines for management of patients with colon and rectal cancer. a personalized approach to clinical decision making. Ann Oncol. 2012; 23:2479-516. https://doi.org/10.1093/annonc/mds236.

26. Umar A, Boland CR, Terdiman JP, Syngal S, de la Chapelle A, Rüschoff J, Fishel R, Lindor NM, Burgart LJ, Hamelin R, Hamilton SR, Hiatt RA, Jass J, et al. Revised Bethesda Guidelines for hereditary nonpolyposis colorectal cancer (Lynch syndrome) and microsatellite instability. J Natl Cancer Inst. 2004; 96:261-8.

27. Campanella NC, Berardinelli GN, Scapulatempo-Neto C, Viana D, Palmero EI, Pereira R, Reis RM. Optimization of a pentaplex panel for MSI analysis without control DNA in a Brazilian population: correlation with ancestry markers. Eur J Hum Genet. 2014; 22:875-80. https://doi.org/10.1038/ejhg.2013.256.

28. Buhard O, Cattaneo F, Wong YF, Yim SF, Friedman E, Flejou JF, Duval A, Hamelin R. Multipopulation analysis of polymorphisms in five mononucleotide repeats used to determine the microsatellite instability status of human tumors. J Clin Oncol. 2006; 24:241-51. https://doi.org/10.1200/JCO.2005.02.7227.

29. Buhard O, Suraweera N, Lectard A, Duval A, Hamelin R. Quasimonomorphic mononucleotide repeats for high-level microsatellite instability analysis. Dis Markers. 2004; 20:251-7. 
30. Slaby O, Sobkova K, Svoboda M, Garajova I, Fabian P, Hrstka R, Nenutil R, Sachlova M, Kocakova I, Michalek J, Smerdova T, Knoflickova D, Vyzula R. Significant overexpression of Hsp110 gene during colorectal cancer progression. Oncol Rep. 2009; 21:1235-41.

31. Jass JR. Classification of colorectal cancer based on correlation of clinical, morphological and molecular features. Histopathology. 2007; 50:113-30. https://doi.org/10.1111/j.1365-2559.2006.02549.x.

32. Buhard O, Lagrange A, Guilloux A, Colas C, Chouchene M, Wanherdrick K, Coulet F, Guillerm E, Dorard C, Marisa L, Bokhari A, Greene M, El-Murr N, et al. HSP110 T17 simplifies and improves the microsatellite instability testing in patients with colorectal cancer. J Med Genet. 2016; 53:377-84. https://doi.org/10.1136/jmedgenet-2015-103518.

33. Goel A, Nagasaka T, Hamelin R, Boland CR. An optimized pentaplex PCR for detecting DNA mismatch repairdeficient colorectal cancers. PLoS One. 2010; 5:e9393. https://doi.org/10.1371/journal.pone.0009393.

34. Vilar E, Tabernero J. Molecular dissection of microsatellite instable colorectal cancer. Cancer Discov. 2013; 3:502-11. https://doi.org/10.1158/2159-8290.CD-12-0471.

35. Stoffel EM, Mangu PB, Gruber SB, Hamilton SR, Kalady MF, Lau MW, Lu KH, Roach N, Limburg PJ, and American Society of Clinical Oncology, and European Society of Clinical Oncology. Hereditary colorectal cancer syndromes: american society of clinical oncology clinical practice guideline endorsement of the familial riskcolorectal cancer: european society for medical oncology clinical practice guidelines. J Clin Oncol. 2015; 33:209-17. https://doi.org/10.1200/JCO.2014.58.1322.

36. Gupta S, Provenzale D, Regenbogen SE, Hampel H, Slavin TP Jr, Hall MJ, Llor X, Chung DC, Ahnen DJ, Bray T, Cooper G, Early DS, Ford JM, et al. NCCN Guidelines Insights: genetic/familial high-risk assessment: colorectal, version 3.2017. J Natl Compr Canc Netw. 2017; 15:146575. https://doi.org/10.6004/jncen.2017.0176.

37. Patil DT, Bronner MP, Portier BP, Fraser CR, Plesec TP, Liu X. A five-marker panel in a multiplex PCR accurately detects microsatellite instability-high colorectal tumors without control DNA. Diagn Mol Pathol. 2012; 21:127-33. https://doi.org/10.1097/PDM.0b013e3182461cc3.

38. Cicek MS, Lindor NM, Gallinger S, Bapat B, Hopper JL, Jenkins MA, Young J, Buchanan D, Walsh MD, Le Marchand L, Burnett T, Newcomb PA, Grady WM, et al. Quality assessment and correlation of microsatellite instability and immunohistochemical markers among population- and clinic-based colorectal tumors results from the Colon Cancer Family Registry. J Mol Diagn. 2011; 13:271-81. https://doi.org/10.1016/j.jmoldx.2010.12.004.

39. Zhang L. Immunohistochemistry versus microsatellite instability testing for screening colorectal cancer patients at risk for hereditary nonpolyposis colorectal cancer syndrome. Part II. The utility of microsatellite instability testing. J Mol Diagn. 2008; 10:301-7. https://doi.org/10.2353/jmoldx.2008.080062.
40. Lindor NM, Burgart LJ, Leontovich O, Goldberg RM, Cunningham JM, Sargent DJ, Walsh-Vockley C, Petersen GM, Walsh MD, Leggett BA, Young JP, Barker MA, Jass JR, et al. Immunohistochemistry versus microsatellite instability testing in phenotyping colorectal tumors. J Clin Oncol. 2002; 20:1043-8. https://doi.org/10.1200/JCO.2002.20.4.1043.

41. Lin $\mathrm{CH}$, Lin JK, Chang SC, Chang $\mathrm{YH}$, Chang HM, Liu JH, Li LH, Chen YT, Tsai SF, Chen WS. Molecular profile and copy number analysis of sporadic colorectal cancer in Taiwan. J Biomed Sci. 2011; 18:36. https://doi.org/10.1186/1423-0127-18-36.

42. Xicola RM, Llor X, Pons E, Castells A, Alenda C, Piñol V, Andreu M, Castellví-Bel S, Payá A, Jover R, Bessa X, Girós A, Duque JM, et al, and Gastrointestinal Oncology Group of the Spanish Gastroenterological Association. Performance of different microsatellite marker panels for detection of mismatch repair-deficient colorectal tumors. J Natl Cancer Inst. 2007; 99:244-52. https://doi.org/10.1093/jnci/djk033.

43. Goldstein JB, Wu W, Borras E, Masand G, Cuddy A, Mork ME, Bannon SA, Lynch PM, Rodriguez-Bigas M, Taggart MW, Wu J, Scheet P, Kopetz S, et al. Can microsatellite status of colorectal cancer be reliably assessed after neoadjuvant therapy? Clin Cancer Res. 2017; 23:5246-54. https://doi.org/10.1158/1078-0432.CCR-16-2994.

44. Markovic S, Antic J, Dimitrijevic I, Zogovic B, Bojic D, Svorcan P, Markovic V, Krivokapic Z. Microsatellite instability affecting the T17 repeats in intron 8 of HSP110, as well as five mononucleotide repeats in patients with colorectal carcinoma. Biomark Med. 2013; 7:613-21. https://doi.org/10.2217/bmm.13.46.

45. Wang XY, Chen X, Manjili MH, Repasky E, Henderson R, Subjeck JR. Targeted immunotherapy using reconstituted chaperone complexes of heat shock protein 110 and melanoma-associated antigen gp100. Cancer Res. 2003; 63:2553-60.

46. Andreasson C, Fiaux J, Rampelt H, Druffel-Augustin S, Bukau B. Insights into the structural dynamics of the Hsp110Hsp70 interaction reveal the mechanism for nucleotide exchange activity. Proc Natl Acad Sci U S A. 2008; 105:16519-24. https://doi.org/10.1073/pnas.0804187105.

47. Manjili MH, Wang XY, Chen X, Martin T, Repasky EA, Henderson R, Subjeck JR. HSP110-HER2/neu chaperone complex vaccine induces protective immunity against spontaneous mammary tumors in HER-2/neu transgenic mice. J Immunol. 2003; 171:4054-61.

48. Ceballos E, Munoz-Alonso MJ, Berwanger B, Acosta JC, Hernandez R, Krause M, Hartmann O, Eilers M, Leon J. Inhibitory effect of c-Myc on p53-induced apoptosis in leukemia cells. Microarray analysis reveals defective induction of p53 target genes and upregulation of chaperone genes. Oncogene. 2005; 24:4559-71. https://doi.org/10.1038/sj.onc.1208652.

49. Shia J. Immunohistochemistry versus microsatellite instability testing for screening colorectal cancer patients at risk for hereditary nonpolyposis colorectal cancer syndrome. Part 
I. The utility of immunohistochemistry. J Mol Diagn. 2008; 10:293-300. https://doi.org/10.2353/jmoldx.2008.080031.

50. Murphy KM, Zhang S, Geiger T, Hafez MJ, Bacher J, Berg KD, Eshleman JR. Comparison of the microsatellite instability analysis system and the Bethesda panel for the determination of microsatellite instability in colorectal cancers. J Mol Diagn. 2006; 8:305-11. https://doi.org/10.2353/jmoldx.2006.050092.
51. Kawakami H, Zaanan A, Sinicrope FA. Microsatellite instability testing and its role in the management of colorectal cancer. Curr Treat Options Oncol. 2015; 16:348. https://doi.org/10.1007/s11864-015-0348-2.

52. Cancer Genome Atlas Network. Comprehensive molecular characterization of human colon and rectal cancer. Nature. 2012; 487:330-7. https://doi.org/10.1038/nature11252. 